
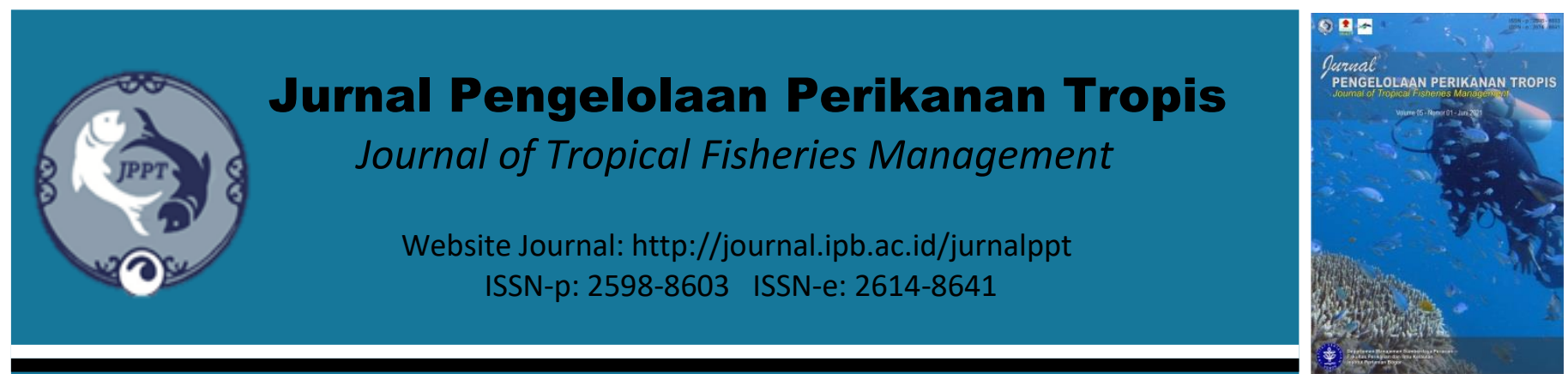

\title{
Status Perikanan Tangkap di Sungai Sebangau dan Katingan, Taman Nasional Sebangau Kalimantan Tengah
}

\author{
(Status for Capture Fisheries in Sebangau and Katingan Rivers, Sebangau National Park Central \\ Kalimantan)
}

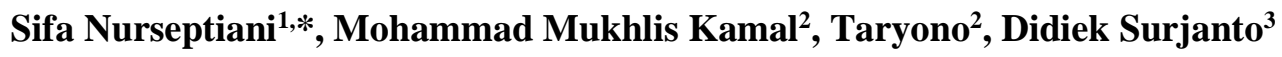

${ }^{1}$ Mahasiswa Departemen Manajemen Sumberdaya Perairan, Fakultas Perikanan dan Ilmu Kelautan, Institut Pertanian Bogor. ${ }^{2}$ Dosen Departemen Manajemen Sumberdaya Perairan, Fakultas Perikanan dan Ilmu Kelautan, Institut Pertanian Bogor. ${ }^{3}$ Community Foresty Expert WWF Kalimantan Tengah Indonesia.
\end{abstract}

\section{INFO ARTIKEL}

Histori Artikel

Recevied: 16 Desember 2021

Accepted: 22 Februari 2021

Kata Kunci:

nelayan; penangkapan;

Katingan; Sebangau; Sungai

Keywords:

capture fisheries;

fishermen; Katingan; river;

Sebangau

\section{Korespondensi Author}

Sifa Nurseptiani, Departemen

Manajemen Sumberdaya

Perairan, Fakultas Perikanan dan Ilmu Kelautan, Institut Pertanian Bogor

Email:

sifanurseptiani@outlook.co $\mathrm{m}$

\section{ABSTRAK}

Sebangau dan Katingan sebagian alirannya menjadi batas terluar dari kawasan konservasi Taman Nasional Sebangau (TNS) Kalimantan Tengah. Kedua sungai mendapat pengaruh langsung dari hutan rawa gambut dan menghasilkan karakteristik perairan hitam. Sungai memiliki sumberdaya ikan yang dimanfaatkan melalui kegiatan perikanan tangkap oleh masyarakat sungai, yakni nelayan. Kegiatan penangkapan berlangsung di wilayah induk dan anak sungai sebagai wilayah komunal dan terkontrol. Wilayah penangkapan mempengaruhi kondisi perikanan tangkap, hal ini menjadi permasalahan dalam penelitian ini. Tujuan penelitian ini adalah menguraikan pelaku usaha perikanan, identitas penangkapan, hasil tangkapan, dan wilayah penangkapan. Lokasi penelitian bertempat di induk dan anak Sungai Sebangau dan Katingan, berlangsung dari bulan Oktober hingga Desember 2019. Metode penelitian menggunakan metode deskriptif melalui pendekatan kualitatif. Pengumpulan data primer yaitu observasi, wawancara, dan dokumentasi, data sekunder melalui studi dokumen dari berbagi sumber. Tahapan analisis data terdiri atas tiga tahap yaitu reduksi data, penyajian data, dan penarikan kesimpulan. Hasil penelitian yang dapat adalah usaha perikanan tangkap dilakukan oleh nelayan dengan alat tangkap tradisional. Nelayan memiliki hasil tangkapan berupa ikan konsumsi air tawar yang terdiri dari delapan jenis famili ikan per sungai. Nelayan melakukan penangkapan di bagian induk dan anak sungai. Wilayah penangkapan terdiri atas dua wilayah, yakni wilayah komunal menempati induk Sungai Sebangau dan seluruh wilayah Sungai Katingan dan wilayah terkontrol berlokasi di anak Sungai Sebangau. Wilayah komunal bersifat terbuka sedangkan wilayah terkontrol bersifat tertutup, hal ini mempengaruhi kondisi perikanan yang berlangsung di setiap wilayah.

\section{ABSTRACT}

Sebangau and Katingan Rivers flow becomes the outer boudary of the Sebangau National Park $(S N P)$ conservation area in Central Kalimantan. Both of rivers are directly affected by the peat swamp forest and has characteristics as black waters. The river has fish resources that are utilized through capture fisheries by communities as fishermen. Capture fisheries are located in main and tributary areas as common and control areas. The fishing ground influence the capture fisheries condition, this situation become the problem in this study. The purpose of this research is to describe the fishery actors, the catching identity, the catch, and the fishing ground. The research location is located in the main and tributary of the Sebangau and Katingan Rivers, from October to December 2019. The research method used a descriptive method through a qualitative approach. Primary data collect by observation, interviews, and documentation, secondary data through document study from various sources. Data analysis: data reduction, data display, and verification. The result of this research are fishery business carried out by fishermen with traditional fishing gear. The catch of fishermen is freshwater consumption fish which consists of eight fish families type per river. Fishermen's activities located at main and tributary areas. The fishing ground consist of two areas, common area in Sebangau's main river and all areas on the Katingan River and private area is located at Sebangau's tributary river. Common area as an open access and control area as a private access, this affects the condition of fisheries that take place in each area. 


\section{PENDAHULUAN}

Sungai sebagai salah satu ekosistem perairan darat (PD), menyimpan berbagai manfaat dan peran dalam keseimbangan alam serta kehidupan manusia. Sungai merupakan ekosistem perairan tawar yang mengalir dari bagian hulu ke ruas hilir, tersusun atas komponen biotik dan abiotik. Potensi dan peranannya berkontribusi besar terhadap keseimbangan alam dan berbagai aktivitas kehidupan biota akuatik dan manusia (Sumantriyadi et al. 2017; Agusta dan Ihwan 2019; Santiari 2019). Penelitian ini merujuk pada dua lokasi sungai di Provinsi Kalimantan Tengah yaitu Sungai Sebangau dan Katingan, mengalir sepanjang $\pm 200 \mathrm{~km}$ dan $\pm 650 \mathrm{~km}$ (BPS Kalteng 2020). Secara geografis Sungai Sebangau melintasi Kota Palangkaraya dan Kabupaten Pulang Pisau serta Sungai Katingan berada di Kabupaten Katingan. Kedua sungai mendapat pengaruh langsung dari hutan rawa gambut dan menghasilkan warna perairan coklat kehitaman jernih atau disebut sebagau perairan hitam (black waters), juga menjadi karakteristik dari kedua sungai. Sebagian lintasan aliran sungai, menjadi batas terluar dari kawasan Taman Nasional Sebangau (TNS). Taman Nasional Sebangau merupakan kawasan konservasi berdasarkan Surat Keputusan Menteri Kehutanan yaitu SK.423/Menhut-II/2004 (Zakiah et al. 2015).

Sungai memiliki sumberdaya tinggi terhadap jenis ikan air tawar, kemudian dimanfaatkan melalui kegiatan perikanan tangkap. Hal ini terjadi di Sungai Sebangau dan Katingan, penangkapan dilakukan di wilayah induk dan anak sungai oleh nelayan setempat. Kegiatan penangkapan bersifat tradisional, terlihat dari keberlangsungan aktivitas tangkap yang sepenuhnya menggunakan alat tangkap statis dengan pengoperasian tenaga manusia. Nelayan menentukan daerah tangkapan dengan berpacu terhadap kebiasaan dan pengalaman tanpa sentuhan teknologi. Peninjauan lapangan didapatkan bahwa wilayah penangkapan memiliki kondisi sebagai wilayah komunal dan terkontrol. Wilayah komunal mencakup induk Sungai Sebangau dan seluruh wilayah Sungai Katingan. Wilayah terkontrol menduduki anak Sungai Sebangau. Kondisi wilayah yang ada, mempengarhui status perikanan tangkap di masing-masing wilayah sungai.

Sungai hakikatnya merupakan wilayah perairan umum bersifat terbuka yang dikelola dan dimanfaatkan sumberdayanya (Marbun 2018), kondisi berbeda terjadi pada anak Sungai Sebangau, memiliki wilayah terkontrol. Wilayah komunal ialah wilayah perairan bersifat terbuka (open access) dan wilayah perairan terkontrol ialah wilayah perairan bersifat tertutup (private access). Kedua wilayah memiliki perbedaan pada sistem pengelolaan sungai, dimana wilayah terkontrol dikelola oleh penanggung jawab wilayah, disebut dengan nelayan pemilik hak. Pengelolaan perikanan berbasis hak di beberapa perairan Indonesia merupakan adaptasi konsep dari kearifan lokal, dikenal dengan hak ulayat. Kepemilikan hak ulayat dikuasai secara turun-temurun oleh perorangan maupun kelompok (klan/marga) (Kuswandi et al. 2015). Sistem hak pengelolaan perikanan di peruntukan untuk mendapatkan hak atas pengelolaan wilayah perairan beserta sumberdayanya, dan hak atas kesejahteraan lingkungan hidup (Sulastriyono dan Pradhani 2018). Sumberdaya yang terkandung diartikan tetap milik bersama, tidak dikuasai oleh satu pihak tertentu. Pengelolaan perikanan melibatkan banyak pihak, sehingga pemerintah mengeluarkan Undang-Undang RI Nomor 31 Tahun 2004 untuk mengatur tentang perikanan. Pihak yang berkontribusi besar adalah masyarakat setempat/ adat sebagai pengelola utama. Pemerintah memiliki kewenangan dalam membuat peraturan perundang-undangan untuk melindungi sistem hak masyarakat adat (Yostina 2016). Sistem hak dalam pengelolaan perikanan bertujuan untuk menghindari pemanfaatan sumberdaya secara ilegal (Rachelliana et al. 2016).

Presensi sistem hak pengelolaan menciptakan sebuah mekanisme lokal pada suatu wilayah perairan, keadaan ini yang ditemukan pada anak Sungai Sebangau. Mekanisme lokal mempunyai makna dalam mempertahankan sumberdaya ikan dan mata pencaharian masyarakat sungai. Berdasarkan uraian yang ada bahwa pokok permasalahan dalam penelitian ini adalah wilayah penangkapan mempengaruhi kondisi perikanan tangkap yang berlangsung. Tujuan penelitian ini menguraikan pelaku usaha perikanan, identitas penangkapan, jenis ikan hasil tangkapan, dan kondisi wilayah penangkapan. Manfaat penelitian ini adalah memberikan informasi terkait kondisi wilayah perikanan tangkap di perairan darat.

\section{METODE}

\section{Waktu dan Lokasi Penelitian}

Penelitian ini dilaksanakan pada bulan Oktober hingga Desember 2019 di Sungai Sebangau dan Katingan, kawasan TN Sebangau, Kalimantan Tengah. Penelitian bertempat di kediaman (pondokan) nelayan berada di wilayah induk dan anak-anak Sungai Sebangau dan Katingan. Peta penelitian tersaji dalam Gambar 1. 


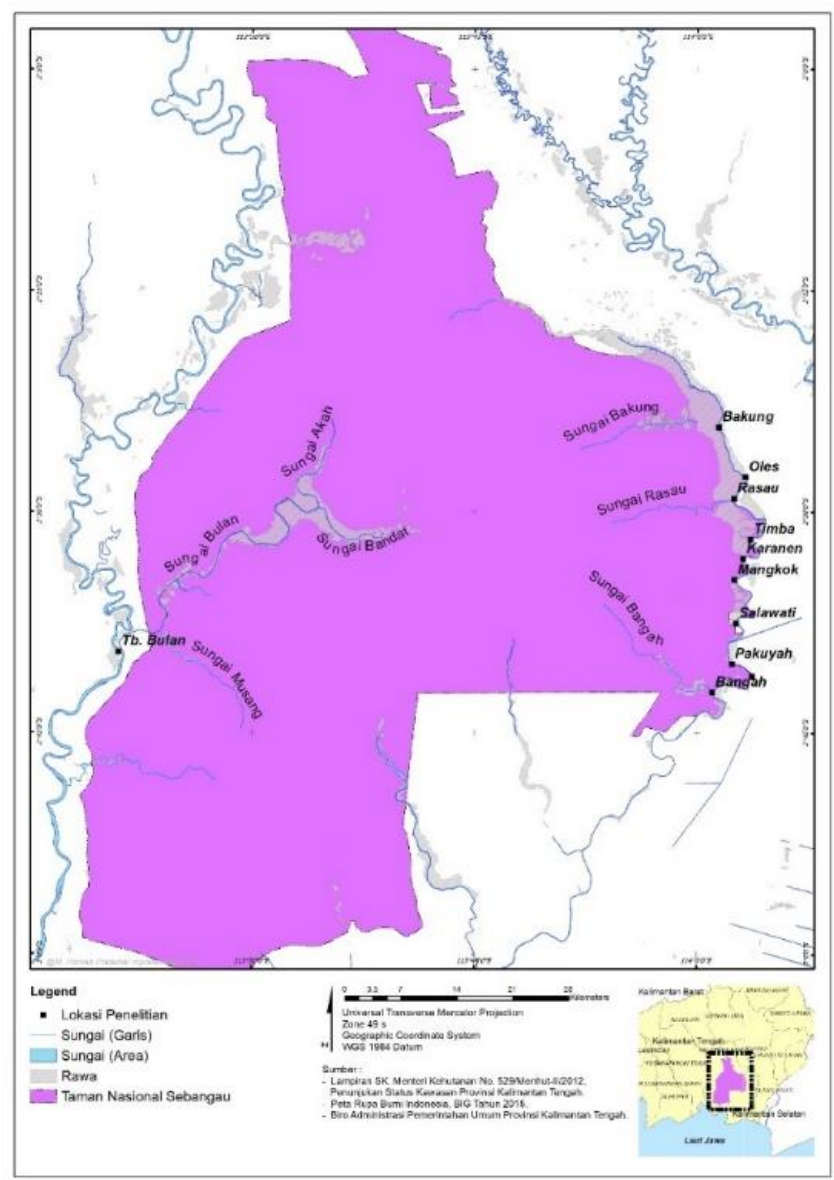

Gambar 1. Peta penelitian di aliran Sungai Sebangau dan Katingan

\section{Pendekatan Penelitian}

Penelitian ini menggunakan metode deskriptif melalui pendekatan kualitatif. Metode deskriptif digunakan untuk menggambarkan data berdasarkan fakta lapangan secara faktual (Yuliasari et al. 2013; Sirait dan Pinem 2019). Pendekatan kualitatif digunakan untuk memperoleh data melalui pengamatan, rekaman, wawancara, atau bahan tertulis saat pelaksanaan penelitian (Fyka dan Arif 2017). Metode deskriptif kualitatif bertujuan untuk mendokumentasikan data dalam bentuk audio, video, visual, dan bahan tertulis serta melakukan analisis dan pengembangan data dalam memecahkan permasalahan penelitian. Penulis berupaya menjelaskan kemurnian data secara sistematis dan mudah dimengerti oleh banyak pihak (Husuna et al. 2017; https://kbbi.web.id/).

\section{Pengumpulan Data}

Data penelitian terdiri atas data primer dan data sekunder. Proses pengumpulan data primer merujuk kepada Suharyanto et al. (2017), yakni meliputi teknik observasi, wawancara, dan dokumentasi. Pengumpulan data sekunder digunakan untuk memperkuat data penelitian melalui studi dokumen dari berbagi sumber seperti buku, jurnal, hasil penelitian ilmiah, serta media internet dalam proses pengkajian. Proses pengkajian antara catatan lapangan tertulis dan berbagai dokumen menurut Harahap et al. (2019) harus dikaitkan relevansinya terhadap penelitian, sehingga data dapat dijadikan pembanding dan validasi data untuk mempertahakan keabsahan penelitian.

Pertama, observasi atau pengamatan langsung lapangan bertujuan untuk memperoleh gambaran dan keakuratan data primer penelitian. Data yang diamati mencakup kondisi fisik sungai, hasil perikanan tangkap, dan nelayan. Pengumpulan data dilakukan dengan mengunjungi kediaman (pondokan) nelayan di induk dan anak sungai. Anak Sungai Sebangau yang terlibat yaitu Sungai Bakung, Rasau, dan Bangah serta anak Sungai Katingan yaitu Sungai Bulan dan Musang. Kedua, proses wawancara dilakukan secara terstruktur menggunakan penyusunan kuesioner. Informan dipilih menggunakan teknik tidak acak (non probability sampling) yaitu menentukan informan dengan kriteria dari peneliti untuk mendapatkan data penelitian. Informan utama penelitian adalah nelayan sungai digunakan rumus Slovin untuk mendapatkan sampel sebanyak 30 individu. Ketiga, pendokumentasian yaitu hasil observasi dan wawancara didapat dalam bentuk gambar, suara, tulisan, dan video. Informasi yang terkumpul dilanjutkan ketahap penyeleksian data, kemudian diolah kedalam naskah dalam bentuk tulisan dan 
dukungan visualisasi gambar. Dokumentasi merupakan bukti dan keterangan untuk menunjang hasil observasi dan keberlangsungan proses wawancara (Qodir 2011; Fatimah 2016; Amril 2017; Husuna et al. 2017).

\section{Analisis Isi}

Analisis isi digunakan untuk mengarsipkan dan mengkerucutkan subjektivitas data penelitian (Aristyanita et al. 2018; Sari 2018). Analisis isi bertujuan dalam melaporkan hasil data dalam bentuk deskriptif secara sistematis, melalui tiga tahap besar, yaitu reduksi data, penyajian data, dan penarikan kesimpulan. Proses analisis isi merupakan rangkaian dari peninjauan ulang atas pokok permasalahan penelitian untuk memastikan keakuratan antar sumber data.

\section{HASIL DAN PEMBAHASAN}

\section{Hasil}

\section{Pelaku usaha perikanan tangkap}

Nelayan berkedudukan sebagai pelaku usaha perikanan tangkap. Data didapatkan melalui teknik wawancara menggunakan kuesioner kepada 30 individu per sungai. Pengumpulan data meliputi

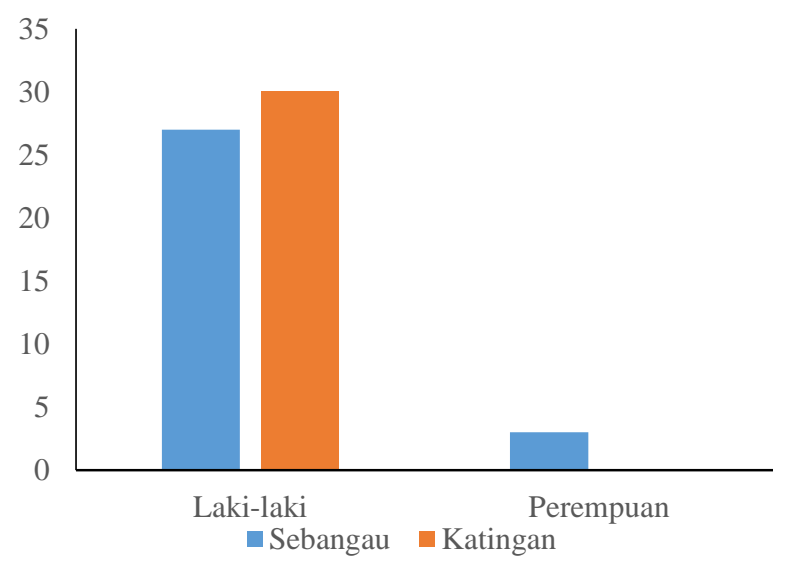

Gambar 2. Profil informan berdasarkan jenis kelamin

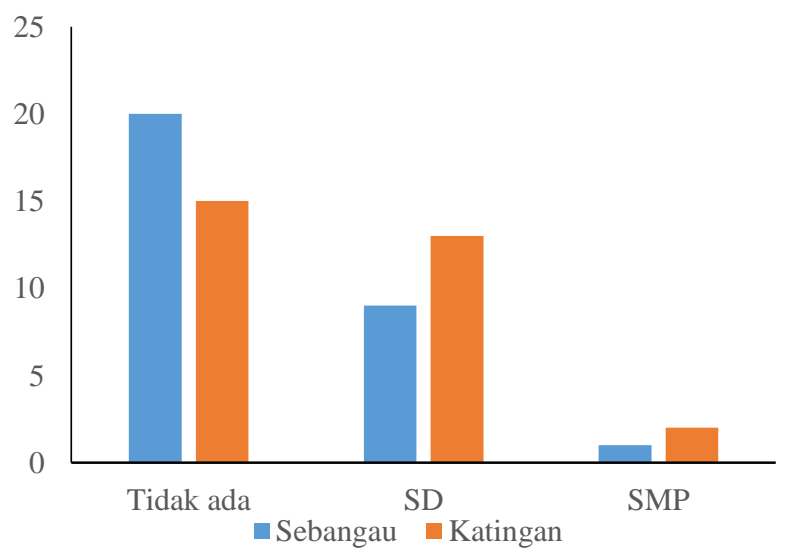

Gambar 4. Profil informan berdasarkan tingkat pendidikan jenis kelamin, umur, tingkat pendidikan, dan asal kependudukan.

\section{Identitas penangkapan}

Identitas penangkapan menguraikan jenis alat tangkap ikan yang digunakan nelayan sungai. Data menyebutkan bahwa alat tangkap yang digunakan adalah alat tangkap tradisional bersifat statis (Tabel 1), bertujuan untuk menghindari kerusakan alam. Tidak ada aturan terkait jumlah, jenis, dan mata jaring alat tangkap. Hal ini memiliki kekhawatiran terhadap penangkapan berlebih. Dimana, nelayan yang memiliki modal usaha tinggi akan membuat dan membeli alat tangkap dalam jumlah besar dan bervariatif. Pengaturan mata jaring berfungsi untuk menyeleksi ukuran hasil tangkapan.

\section{Jenis ikan tangkapan}

Kedua sungai mendapat pengaruh langsung dari hutan rawa gambut dan menghasilkan warna perairan coklat kehitaman jernih atau perairan hitam (black waters). Kondisi ini mempengaruhi ketersediaan sumberdaya ikan yang ada, yakni memiliki dominasi warna gelap. Jenis ikan hasil tangkapan nelayan merupakan jenis ikan konsumsi air tawar (Tabel 2).

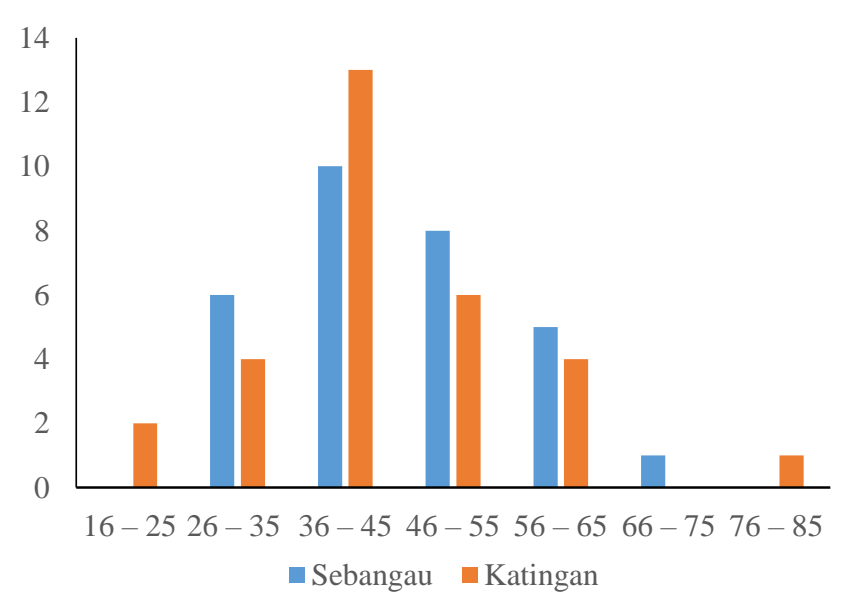

Gambar 3. Profil informan berdasarkan golongan umur

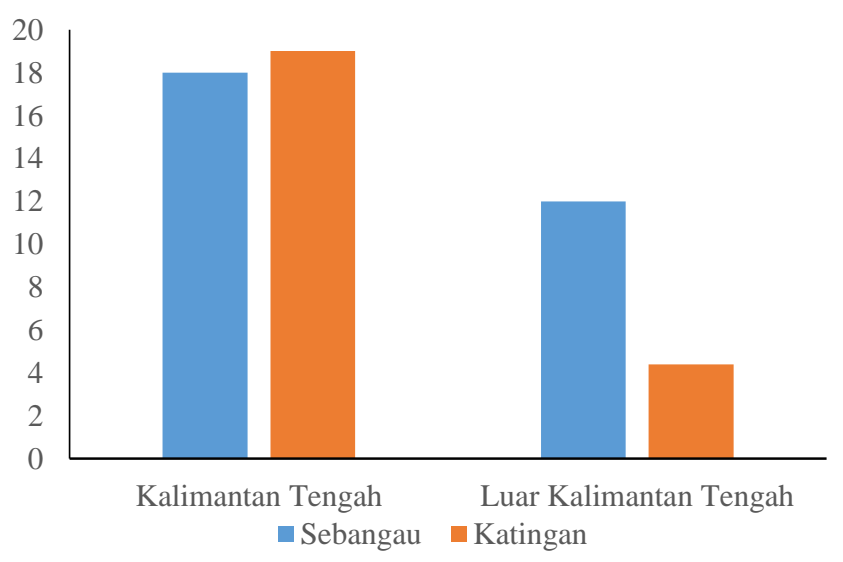

Gambar 5. Profil informan berdasarkan asal kependudukan 
Jurnal Pengelolaan Perikanan Tropis (Journal of Tropical Fisheries Management), Juni 2021, Volume 05 Nomor 01

Tabel 1. Jenis alat tangkap tradisional nelayan Sebangau dan Katingan

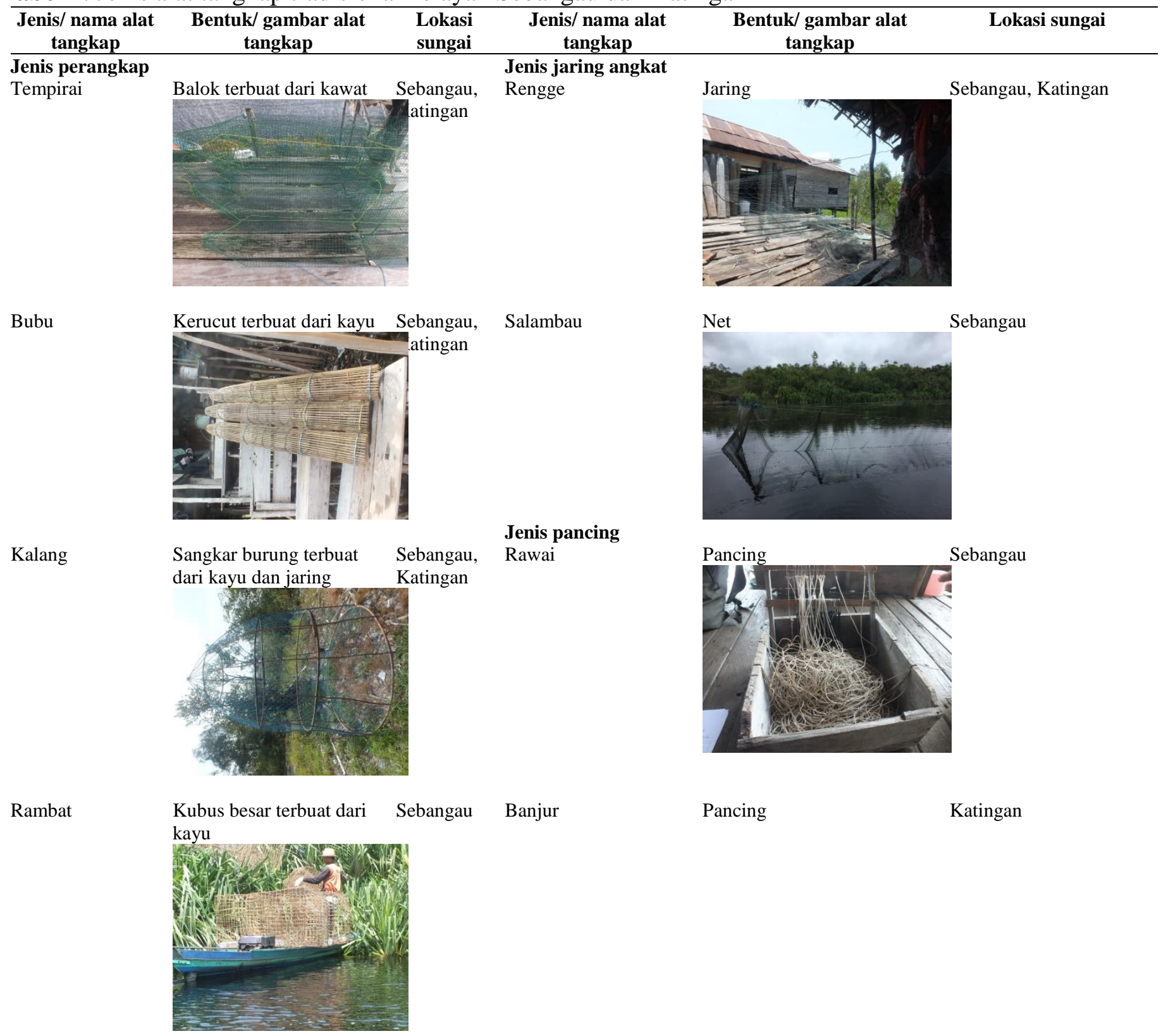

Pengilar

Balok terbuat dari rotan Sebangau,

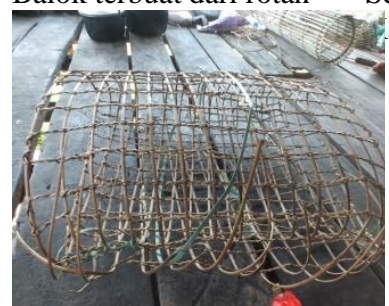

Pakang

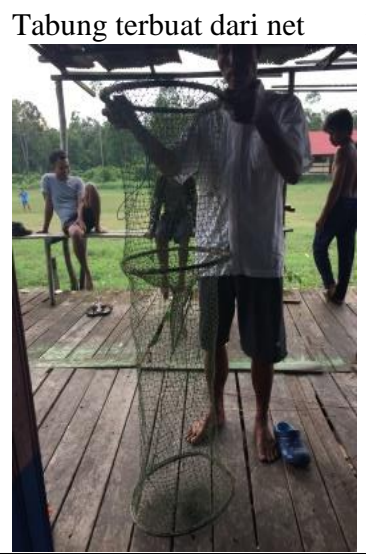


Tabel 2. Jenis ikan tangkapan nelayan Sebangau dan Katingan selama penelitian

Famili, spesies ikan $\quad \begin{gathered}\text { Nama lokal/ } \\ \text { internasional }\end{gathered} \quad$ Lokasi Sungai $\quad$ Famili, spesies ikan $\quad \begin{gathered}\text { Nama lokal/ } \\ \text { internasional }\end{gathered}$ Lokasi Sungai

\begin{tabular}{|c|c|c|c|c|c|}
\hline \multicolumn{3}{|l|}{ Anabantidae } & \multicolumn{3}{|l|}{ Cyprinidae } \\
\hline 1. Anabas testudineus & $\begin{array}{l}\text { Papuyu/ } \\
\text { Climbing perch }\end{array}$ & $\begin{array}{l}\text { Sebangau, } \\
\text { Katingan }\end{array}$ & $\begin{array}{l}\text { 1. Brevibora } \\
\text { dorsiocellata }\end{array}$ & $\begin{array}{l}\text { Siluang/ } \\
\text { Eyespot rasbora }\end{array}$ & Sebangau \\
\hline Bagridae & & & Helostomatidae & & \\
\hline 1. Hemibagrus nemurus & $\begin{array}{l}\text { Baung/ } \\
\text { Asian redtail catfish }\end{array}$ & Katingan & $\begin{array}{l}\text { 1. Helostoma } \\
\text { temminckii }\end{array}$ & $\begin{array}{l}\text { Biawan/ } \\
\text { Kissing gourami }\end{array}$ & $\begin{array}{l}\text { Sebangau, } \\
\text { Katingan }\end{array}$ \\
\hline Channidae & & & Osphronemidae & & \\
\hline 1. Channa striata & $\begin{array}{l}\text { Haruan/ } \\
\text { Striped snakehead }\end{array}$ & $\begin{array}{l}\text { Sebangau, } \\
\text { Katingan }\end{array}$ & 1. Belontia hasselti & $\begin{array}{l}\text { Kapar/ } \\
\text { Malay combtail }\end{array}$ & $\begin{array}{l}\text { Sebangau, } \\
\text { Katingan }\end{array}$ \\
\hline $\begin{array}{l}\text { 2. Channa } \\
\text { pleurophthalma }\end{array}$ & $\begin{array}{l}\text { Kerandang/ } \\
\text { Ocellated snakehead }\end{array}$ & $\begin{array}{l}\text { Sebangau, } \\
\text { Katingan }\end{array}$ & Pristolepididae & & \\
\hline 3. Channa lucius & $\begin{array}{l}\text { Kihung/ } \\
\text { Splendid snakehead }\end{array}$ & $\begin{array}{l}\text { Sebangau, } \\
\text { Katingan }\end{array}$ & $\begin{array}{l}\text { 1. Pristolepis } \\
\text { fasciatus }\end{array}$ & $\begin{array}{l}\text { Patung/ } \\
\text { Malayan leaffish }\end{array}$ & $\begin{array}{l}\text { Sebangau, } \\
\text { Katingan }\end{array}$ \\
\hline 4. Channa bankanensis & $\begin{array}{l}\text { Mihau/ } \\
\text { Bangka snakehead }\end{array}$ & $\begin{array}{l}\text { Sebangau, } \\
\text { Katingan }\end{array}$ & Siluridae & & \\
\hline 5. Channa marulioides & $\begin{array}{l}\text { Peyang/ } \\
\text { Emperor snakehead }\end{array}$ & Sebangau & 1. Wallagonia leerii & $\begin{array}{l}\text { Tapah/ } \\
\text { Giant Malayan } \\
\text { catfish }\end{array}$ & $\begin{array}{l}\text { Sebangau, } \\
\text { Katingan }\end{array}$ \\
\hline 6. Channa micropeltes & $\begin{array}{l}\text { Toman/ } \\
\text { Giant snakehead }\end{array}$ & $\begin{array}{l}\text { Sebangau, } \\
\text { Katingan }\end{array}$ & 2. Ompok miostoma & $\begin{array}{l}\text { Selais/ } \\
\text { Goan catfish }\end{array}$ & Katingan \\
\hline \multicolumn{6}{|l|}{ Clariidae } \\
\hline 1. Clarias meladerma & $\begin{array}{l}\text { Lele/ } \\
\text { Blackskin catfish }\end{array}$ & $\begin{array}{l}\text { Sebangau, } \\
\text { Katingan }\end{array}$ & & & \\
\hline
\end{tabular}

Tabel 3. Aturan penangkapan Sungai Sebangau dan Sungai Katingan

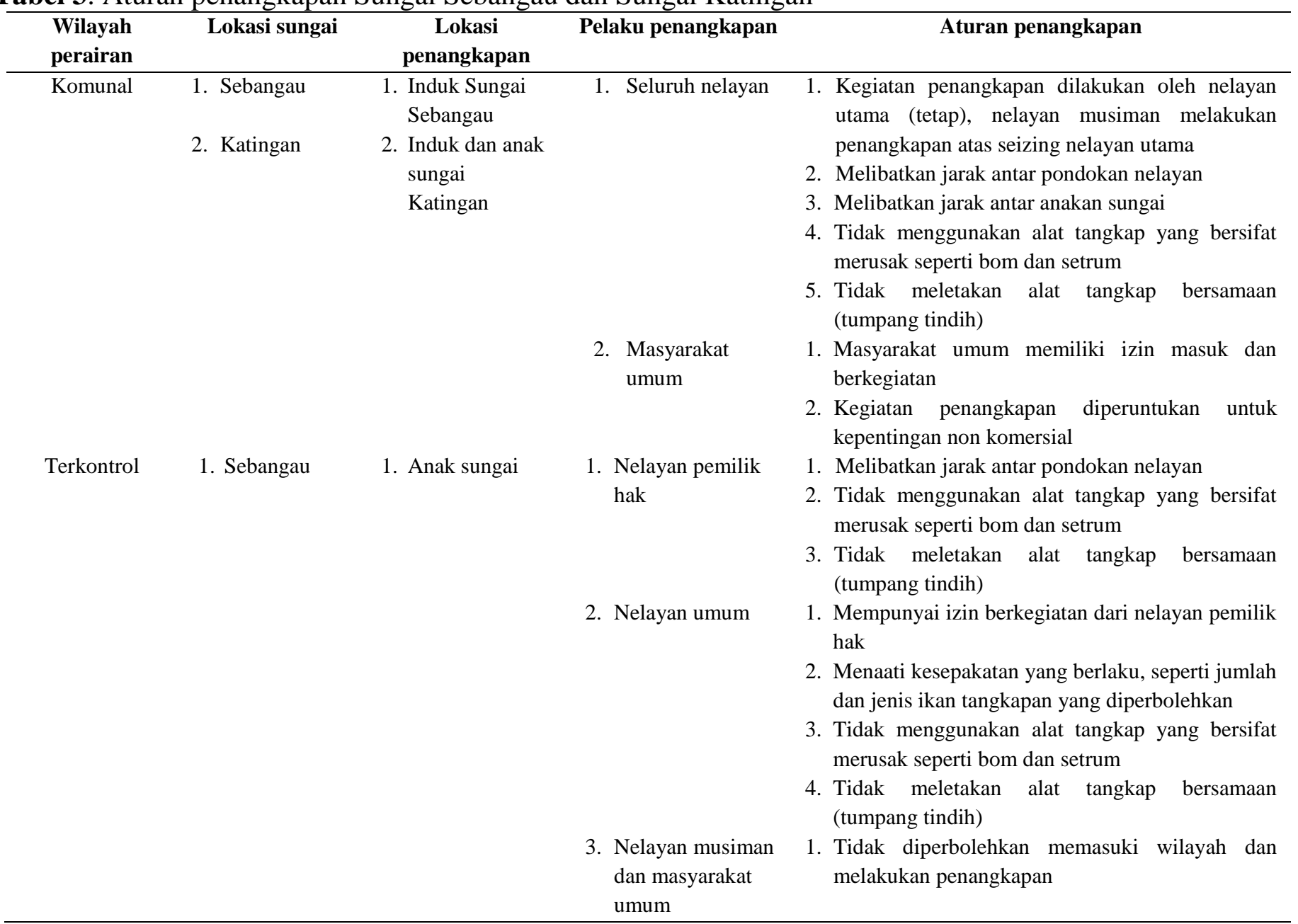




\section{Wilayah penangkapan}

Aliran Sungai Sebangau dan Katingan yang masuk kedalam zona pemanfaatan TN Sebangau diperuntukan sebagai wilayah penangkapan, baik wilayah komunal dan terkontrol. Wilayah komunal terdiri dari induk Sungai Sebangau dan seluruh wilayah Sungai Katingan, sedangkan wilayah terkontrol menempati anak Sungai Sebangau. Luasnya kedua sungai penelitian ini menempati induk Sungai Sebangau yang melintasi anak Sungai Bakung, Rasau, dan Bangah. Adapun anak Sungai Katingan yang terlibat yaitu Sungai Bulan dan Musang. Kondisi sungai membawa terhadap aturan dalam menempati wilayah penangkapan (Tabel 3).

\section{Pembahasan}

Nelayan di kedua sungai didominasi oleh pekerja laki-laki, adapun Sungai Sebangau melibatkan tiga nelayan perempuan. Grafik terkait golongan umur, menunjukkan rentan usia 36-45 tahun memiliki koresponden terbanyak. Golongan usia tersebut dikategorikan sebagai usia dewasa dan produktif (Kautsari et al. 2019). Profesi nelayan merupakan pekerjaan yang berhubungan langsung dengan kondisi alam sehingga membutuhkan kondisi fisik prima dan tenaga besar. Usia produktif akan mempengaruhi kinerja kerja dan nilai pendapatan (Tiani et al. 2017).

Berdasarkan jumlah responden, tingkat pendidikan responden tergolong sangat rendah. Hal ini dilihat melalui jumlah terbanyak diduduki oleh tingkat tidak ada (tidak bersekolah) dan tingkat pendidikan tertinggi adalah SMP. Keadaan tersebut disebabkan responden telah menjalani kehidupan menetap di tepi aliran sungai dan ikut serta dalam kegiatan perikanan tangkap secara turun-temurun. Keadaan masyarakat sungai sangat sulit mendapatkan akses pendidikan, sebab adanya tiga faktor utama penghambat yaitu jarak, waktu, dan biaya. Berdasarkan penelusuran bahwa ketiga faktor saling berkesinambungan. Jarak yang jauh membutuhkan waktu yang lama serta tingginya biaya perjalanan. Penempuhan melalui transportasi air mempunyai biaya relatif cukup tinggi dalam melakukan satu kali perjalanan. Penduduk dikedua sungai dikuasi oleh masyarakat lokal provinsi Kalimatan Tengah yaitu Kota Palangkaraya, Kabupaten Pulang Pisau, dan Kabupaten Katingan. Penduduk pendatang sebagian besar berasal dari provinsi Kalimatan Selatan.

Nelayan Sebangau dan Katingan menggunakan alat tangkap tradisional bersifat statis, yang sebagian besar digerakan oleh tenaga manusia (Tabel 1). Setiap sungai memiliki empat jenis alat tangkap utama, dua di antaranya adalah tempirai dan kalang. Tempirai sebagai alat tangkap utama yang paling banyak digunakan oleh nelayan. Kalang merupakan alat tangkap yang berasal dari Sungai Katingan, kemudian dibawa ke Sungai Sebangau dan diterima oleh nelayan setempat. Kedua alat tangkap bersifat tenggelam, nelayan menggunakan tambahan pelampung sebagai penanda pemasangan alat tangkap. Alat tangkap tambahan memiliki lebih banyak variasi, namun tidak semua nelayan memiliki alat tangkap tambahan sebab terhalang oleh modal usaha dan kinerja kerja. Sungai Sebangau mempunyai alat tangkap tambahan yaitu rawai dan selambau, serta Sungai Katingan mempunyai pakang dan banjur. Rawai dan banjur merupakan jenis pancing, rawai menggunakan mata pancing yang dipasang pada tali sepanjang 5, 10, dan 15 meter. Banjur merupakan jenis pancing yang menggunakan sebilah bambu tipis. Nelayan melibatkan pengalaman dan kebiasaan bekerja dalam meletakkan alat tangkap. Jumlah dan jenis alat tangkap mempengaruhi hasil tangkapan. Sungai Sebangau dan Katingan belum memiliki aturan terkait penggunaan alat tangkap, hal ini menimbulkan kekhawatiran terhadap penangkapan berlebih.

Kegiatan penangkapan sangat dipengaruhi oleh kondisi alam dan kemampuan manusia. Kondisi alam meliputi cuaca, musim penangkapan, dan kondisi wilayah. Musim penangkapan terjadi saat musim penghujan sebab kondisi air tinggi diikuti dengan kelimpahan jenis dan jumlah tangkapan. Faktor kondisi wilayah meliputi morfologi sungai, jenis tanah, dan luas daerah tangkapan sungai juga mempengaruhi hasil tangkapan (Maulana et al. 2017). Kemampuan pekerja, yaitu kinerja kerja, pengalaman, dan modal usaha menjadi dukungan terbesar dalam mencari ikan (Juliastuti et al. 2016; Muna et al. 2016).

Musim penangkapan nelayan yang diserap melalui bahasa daerah setempat diadaptasi berdasarkan naskah Mahin (2011). Musim surung layap merupakan masa peralihan dari musim kemarau menuju musim penghujan, dimana kondisi air permukaan mulai naik dari bulan Oktober-November. Bulan Desember sebagai awal dari musim penghujan untuk memasuki musim danum manahan yang dipercaya sebagai masa kejayaan penangkapan, berlangsung dari bulan Desember-Maret. Pertengahan hingga akhir bulan Maret intensitas hujan mulai berkurang dan air mulai berangsung menurun hingga bulan Juni disebut dengan musim marintak. Musim pandang merupakan musim paceklik tangkapan, yakni 
musim dengan kondisi air rendah menyebabkan jenis dan jumlah tangkapan rendah.

Hasil tangkapan nelayan dikategorikan menjadi dua golongan yaitu hasil tangkapan utama dan tambahan. Jenis ikan tangkapan utama yaitu jenis ikan yang tersedia dan di tangkap sepanjang tahun. Jenis ikan tangkapan tambahan yaitu jenis ikan yang tersedia pada musim tertentu. Tabel 2 menunjukkan kedua sungai memiliki keberagaman jenis tangkapan yang hampir sama, setiap sungai memiliki delapan jenis kelompok famili ikan. Hal ini disebabkan oleh kedua sungai memiliki kondisi lingkungan yang sama. Namun berdasarkan pengamatan lapangan, induk Sungai Katingan memiliki warna perairan coklat keruh, hal ini menimbulkan kekhawatiran terhadap keberadan sumberdaya ikan. Spesies ikan dari kelompok famili Channidae memiliki spesies tertinggi pertama kemudian terdapat famili Siluridae memiliki dua spesies ikan. Nelayan memaparkan bahwa hasil tangkapan utama dikedua sungai yaitu ikan kapar (Belontia hasselti), lele (Clarias meladerma), toman (Channa micropeltes), dan kerandang (Channa pleurophthalma). Hasil tangkapan tambahan lebih bervariatif di antaranya terdapat induk ikan tapah di Sungai Sebangau dan ikan selais di Sungai Katingan. Spesies ikan lainnya yaitu ikan papuyu, patungm dan biawan yang ditemukan di kedua sungai.

Wilayah perairan, hakikatnya merupakan wilayah komunal, penelitian ini menemukan kondisi berbeda yakni adanya wilayah terkontrol di Sungai Sebangau. Kedua wilayah perairan diperuntukan sebagai wilayah penangkapan, berlangsung di induk dan anak sungai. Wilayah komunal menempati induk Sungai Sebangau dan seluruh wilayah Sungai Katingan. Wilayah perairan komunal yaitu wilayah bersifat terbuka (open access) dengan sumberdaya yang terkandung adalah milik bersama (common property) (Eliana 2019). Wilayah perairan terkontrol terkontrol menempati anak Sungai Sebangau yaitu Sungai Bakung, Rasau, dan Bangah. Wilayah perairan terkontrol yaitu wilayah bersifat tertutup (private access) dengan sumberdaya milik bersama dan memiliki pengelola wilayah, baik individu dan/ atau kelompok. Kondisi ini menciptakan mekanisme lokal dan memberlakukan aturan lokal, sebagian besar aturan berasal dari pengelola wilayah untuk masyarakat umum. Mekanisme lokal berfungsi untuk mencegah, mengurangi, dan mengendalikan kerusakan alam, melindungi dan melestarikan lingkungan beserta sumberdayanya, menjaga jalur transportasi umum untuk menghindari kegiatan eksplotiasi oleh orang asing. Masyarakat umum berkewajiban tunduk pada ketentuan yang relevan (Putra et al. 2016).

Tabel 3 menguraikan kondisi yang terjadi di wilayah komunal dan terkontrol, merujuk pada aturan penangkapan yang berlangsung. Wilayah komunal memiliki sifat terbuka, sehingga terbuka bebas untuk jalur transportasi dan kegiatan penangkapan oleh seluruh pihak. Nelayan sungai terdiri dari nelayan tetap dan musiman, nelayan tetap sebagian besar menjalani kehidupan di tepi aliran sungai. Nelayan Sebangau menggunakan pondokan berupa rumah panggung dan nelayan Katingan mempunyai bangunan yang lebih permanen hingga membentuk perkampungan nelayan. Nelayan musiman merupakan masyarakat yang bekerja saat musim tertentu, seperti musim puncak penangkapan. Nelayan tetap memiliki posisi utama dalam melakukan penangkapan di wilayah komunal sedangkan nelayan musiman harus memiliki izin kepada nelayan tetap untuk berkegiatan. Hal ini menghindari terjadinya konflik sosial, perusakan lingkungan, dan pencurian hasil tangkapan. Adapun masyarakat umum (non nelayan) melakukan penangkapan sebatas untuk kegiatan non komersial, seperti rekreasi.

Wilayah komunal memiliki ruang gerak yang lebih terbatas, sebab adanya pengelola wilayah yaitu nelayan pemilik hak. Hak ini merupakan hak pengelolaan, tidak merujuk kepada hak kepemilikan wilayah dan sumberdaya. Sistem pemberian hak didapatkan melalui ikatan kekeluarga inti dan besar yang diturunkan berkelanjutan berdasarkan hubungan darah dan pernikahan sehingga tidak dapat di jual belikan kepada masyarakat umum. Hasil penelitan mendapatkan bahwa Sungai Bakung dan Bangah dikelola oleh keluarrga besar serta Sungai Rasau dikelola oleh keluarga ini. Sistem pemberian hak kepada generasi penerusnya di Sungai Rasau dan Bangah diberikan kepada anggota keluarga yang aktif dalam melakukan pengelolaan sungai dan kegiatan perikanan. Sungai Bakung menurunkan hak kepada anak yang dipilih berdasarkan usia, jenis kelamin ditambah dengan pertimbangan terhadap kontribusi kegiatan sungai. Nelayan pemilik hak mempunyai kontrol terhadap seluruh kegiatan yang berlangsung di wilayahnya. Masyarakat non pemilik hak, baik nelayan maupun masyarakat umum memiliki kewajiban untuk mendapatkan izin dan kesepakatan bersama untuk berkegiatan di wilayah terkontrol. Seluruh wilayah Sungai Sebangau dan Katingan yang masuk kedalam kawasan TN Sebangau tetap mendapat 
kontrol Balai TN Sebangau dalam berkegiatan untuk menghindari adanya eksploitasi sumberdaya.

Gambaran yang ada bahwa wilayah penangkapan mempengaruhi status perikanan tangkap yang berlangsung. Kegiatan penangkapan yang berlangsung di wilayah komunal bersifat terbuka maka status perikanan yang berlangsung adalah perikanan terbuka (open access fishery). Wilayah terkontrol dengan mekanisme lokal, yakni memiliki pengelola sungai sehingga kegiatan penangkapan yang berlangsung disebut dengan perikanan berbasis hak (right-based fishery). Nelayan non hak tidak merasa diberatkan dalam kondisi ini, sebab hasil tangkapan di wilayah komunal masih tergolong tinggi. Nelayan non hak sesekali melakukan penangkapan di wilayah terkontrol untuk mendapatkan jenis ikan tertentu. Wilayah komunal memiliki kekhawatiran yang lebih tinggi terhadap kerusakan lingkungan dan hasil tangkapan berlebih, maka wilayah terkontrol memiliki peluang untuk mempertahankan sumberdaya ikan dan mata pencaharian masyarakat sungai.

\section{KESIMPULAN}

Nelayan merupakan pelaku utama kegiatan perikanan tangkap. Nelayan Sebangau dan Katingan dikategorikan sebagai nelayan tradisional, satu di antaranya dilihat melalui pengoperasian alat tangkap berupa alat tangkap tradisional. Alat tangkap dioperasikan melalui tenaga manusia, alat tangkap menjadi satu di antara modal usaha yang harus dimiliki nelayan. Jenis hasil tangkapan berupa ikan konsumsi air tawar, dengan spesies terbanyak dari kelompok family Channidae. Nelayan melakukan penangkapan di wilayah komunal dan terkontrol, wilayah komunal bersifat terbuka maka perikanan yang berlangsung adalah perikanan terbuka. Wilayah terkontrol bersifat tertutup memiliki kondisi perikanan berbasis hak.

\section{UCAPAN TERIMA KASIH}

Ucapan terimakasih kepada Allah SWT dan orang tua sebagai pendukung terbesar dalam penelitian ini. Kepada Bapak Dr. M. Mukhlis Kamal, M.Sc dan Bapak Dr. Taryono, M.Si sebagai dosen pembimbing Departemen Manajemen Sumberdaya Perairan IPB. Bapak Didiek Surjanto, Okta Simon, dan Mamun Ansori beserta seluruh tim WWF Kalimantan Tengah, Indonesia yang telah membantu sepenuhnya dalam proses pengambilan data lapangan. Beserta seluruh informan atas ketersedian waktu dan tempat yang diberikan untuk wawancara mendalam.

\section{DAFTAR PUSTAKA}

Agusta R, Ihwan. 2019. Kelimpahan plankton pada perairan payau Sungai Batang Naras Kabupaten Padang Pariaman Sumatera Barat. Jurnal Agrominansia. 4(2): 130-145.

Amril. 2017. Pengaruh disiplin kerja dan gaya kepemimpinan terhadap kinerja karyawan. Jurnal Kewirausahaan. 3(2): 59-68.

Aristyanita V, Sudargo T, Ambardi K. 2018. Temu media dan promosi pemberian air susu ibu melalui media massa. Jurnal Kedokteran Masyarakat. 34(4): 167-174.

Badan Pusat Statistik Kalimantan Tengah. 2020. Diunduh

https://kalteng.bps.go.id/statictable/2016/09/ 21/261/nama-nama-sungai-menurut-panjang kedalaman-dan-lebar-di-provinsi-

kalimantan-tengah.html/ tanggal 12 Februari 2020 .

Eliana. 2019. Kepastian hukum kepemilikan tanah ulayat kaum Adat Baduy. Journal of Law. 2(2): 111-118.

Fatimah. 2016. Pengembangan pendidikan karakter dan keunggulan lokal dalam kurikulum kejuruan di SMK Negeri Kabupaten Tapin. Jurnal Pendidikan Kewarganegaraan. 6(11): 882-899.

Fyka JA, Arif LOK. 2017. Kajian kelembagaan dan pemberdayaan masyarakat pesisir kawasan daerah perlindungan laut masyarakat di Kabupaten Wakatobi. Jurnal Buletin Sosial. 36: 128-138.

Harahap YR, Damanik IH, Sibarani R. 2019. Etnografi masyarakat dan hukum adat Kabupaten Humbang Hasundutan Sumatera Utara. Jurnal Pendidikan Ilmu-ilmu Sosial. 11(2): 260-272.

Husuna F, Rantung SV, Kotambunan OO. 2017. Penilaian nelayan terhadap program pengembangan perikanan tangkap Huhate di Kota Bitung Provinsi Sulawesi Utara. Jurnal Ilmiah Agrobisnis Perikanan. 5(9): 667-676.

Juliastuti MT, Mudzakir AK, Hapsari TD. 2016. Analisis faktor produksi alat tangkap jaring insang (gill net) terhadap hasil tangkapan rajungan (Portunus sp.) di Desa Sukoharjo Kabupaten Rembang Jawa Tengah. Journal of Fisheries Resources Utilization Management and Technology. 5(1): 57-66.

Kautsari N, Riani E, Lumbanbatu DTF, Hariyadi S. 2019. Perikanan teripang pesisir (Holuthuria scabra) Teluk Saleh: status stok berdasarkan persepsi nelayan dan hasil tangkapan. Jurnal Ilmiah Perikanan dan Kelautan. 11(2): 5971. 
Kuswandi R, Sadono R, Supriyatno N, Marsono D. 2015. Model pengelolaan hasil hutan kayu oleh masyarakat adat: studi kasus pemilik hak ulayat di Kabupaten Teluk Bintuni. Jurnal Kehutanan Papuasia. 1(1):11-17.

Mahin M. 2011. Kehidupan sosial ekonomi nelayan di Sungai Sebangau, Kalimantan Tengah [Laporan]. Palangkaraya: World Wildlife Fund Kalimantan Tengah Indonesia.

Marbun F. 2018. Lelang lebung: ekspansi kekuasaan, kesadaran ekologis dan strategi ekonomi. Jurnal Penelitian Budaya dan Sejarah. 10(3): 369-384.

Maulana I, Lukita SA, Suharyanto, Pranoto S. 2017. Perencanaan pengendalian anjir Sungai Tuntang Di Desa Trimulyo Kabupaten Demak. Jurnal Karya Teknik Sipil. 6(4): 447-459.

Muna N, Ismail, Jayanto BB. 2016. Analisis faktor produksi jaring insang lingkar (encircling gill net) di PPI Pulolampes Brebes. Journal of Fisheries Resources Utilization Management and Technology. 5(2): 38-47.

Putra TSI, Samekto FXA, Hardiwinoto S. 2016. Reklamasi Pulau Republik Rakyat Tiongkok di Laut Cina Selatan: suatu analisis terhadap status penambahan wilayah dan dampak terhadap jalur pelayaran internasional. Diponegoro Law Review. 5(2): 1-14.

Qodir A. 2011. Analisis kelembagaan dalam upaya pembangunan kesejahteraan masyarakat [Tesis]. Depok: Universitas Indonesia.

Rachelliana R, Trihastuti N, Setyawanta LT. 2016. Implementasi hak pengejaran seketika terhadap pelaku tindak pidana perikanan sesuai konvensi perserikatan bangsa-bangsa tentang hukum laut tahun 1982. Journal of Diponegoro Law. 5(3): 1-16.

Santiari M. 2019. Indeks kualitas air sungai noemuti dan analisis sensitivitas. Jurnal Ilmu Pendidikan Biologi. 4(3): 81-85.

Sari IFR. 2018. Konsep dasar gerakan literasi sekolah pada permendikbud nomor 23 tahun 2015 tentang penumbuhan budi pekerti. Jurnal Pendidikan Dasar Islam. 10(1): 8999.

Sirait M, Pinem M. 2019. Analisis pengembangan potensi obyek wisata pantai di Kabupaten Serdang Bedagei. Jurnal Pendidikan Ilmuilmu Sosial. 11(1): 29-45.

Suharyanto A, Armansyah M, Syafruddin R. 2017. Persepsi masyarakat Kelurahan Tigabalata Kecamatan Jorlang Hataran mengenai usulan pemekaran Kabupaten Simalungun. Jurnal Pendidikan Ilmu-ilmu Sosial. 9(2): 177-185.
Sulastriyono, Pradhani SI. 2018. Pemikiran hukum adat djojodigoeno dan relevansinya kini. Jurnal Mimbar Hukum. 30(3): 449-464.

Sumantriyadi, Wildayana E, Syaifudin M. 2017. Analisis pembesaran ikan patin siam (Pangasius hypophthalmus) terhadap kualitas air sungai komering di Kecamatan Sirah Pulau Padang. Jurnal Ilmu-ilmu Perikanan dan Budidaya Perairan. 12(2): 58-61.

Tiani L, Purnamasari E, Abdusysyahid S. 2017. Persepsi nelayan terhadap larangan penggunaan alat tangkap dogol di Kelurahan Manggar Baru Kecamatan Balikpapan Timur. Jurnal Penyuluhan Perikanan. 11(3): 177-187.

Yuliasari RA, Boesono H, Wijayanto D. 2013. Analisis strategi pengembangan kelembagaan pemasaran ikan komoditas utama di pelabuhan perikanan pantai (PPP) Bajomulyo Kabupaten Pati. Journal of Fisheries Resources Utilization Management and Technology. 2(3): 30-39.

Yostina M. 2016. Hak komunal atas tanah masyarakat hukum adat di Indonesia. Jurnal Mahasiswa Fakultas Hukum Universitas Brawijaya. 5(7): 1-26.

Zakiah W, Maryunani, Fanani Z, Ariyadi M. 2015. Community characteristics Sebangau National Park Buffer zone based sustainable livelihood approach. Journal of Resources and Environment. 5(6): 182-191. 